\title{
Probing genetic overlap in the regulation of systolic and diastolic blood pressure in Danish and Chinese twins
}

\author{
Shuxia $\mathrm{Li}^{1}$, Zengchang Pang ${ }^{2}$, Dongfeng Zhang ${ }^{3}$, Haiping Duan ${ }^{2}$, Jacob von Bornemann Hjelmborg ${ }^{4}$, \\ Qihua Tan ${ }^{1,4,5}$, Torben Arvid Kruse ${ }^{1,5}$ and Kirsten Ohm Kyvik ${ }^{6}$
}

Although the phenotypic correlation between systolic blood pressure (SBP) and diastolic blood pressure (DBP) is well known, the genetic basis for the correlation has rarely been investigated. The aim of this paper is to examine the genetic overlap between SBP and DBP by fitting bivariate models to Danish and Chinese twins and comparing ethnic differences between the two samples. Our estimates revealed a high proportion of additive genetic components shared by both SBP and DBP in Danish (0.71, 95\% confidence interval (CI): $0.65-0.75)$ and Chinese $(0.62,95 \% \mathrm{Cl}: 0.50-0.71)$ twins with no statistically significant ethnic differences. The estimated genetic component in phenotypic correlation could serve to guide molecular genetic studies searching for genetic variants that affect both SBP and DBP. The bivariate model also estimated genetic and environmental contributions to SBP and DBP separately, with an overall pattern of higher genetic regulation or heritability in Danish $(0.72$, 95\% Cl: $0.67-0.76$ for SBP; $0.70,95 \% \mathrm{Cl}: 0.65-0.75$ for DBP) than in Chinese (0.54, 95\% Cl: $0.44-0.63$ for SBP; 0.57 , $95 \% \mathrm{Cl}: 0.47-0.65$ for DBP) twins and a higher contribution from unique environmental factors in Chinese compared with Danish twins. The estimated contribution from unique environmental factors suggests that promoting healthy lifestyles may provide an efficient way of controlling high blood pressure, particularly in the Chinese population.

Hypertension Research (2014) 37, 954-959; doi:10.1038/hr.2014.95; published online 15 May 2014

Keywords: blood pressure; Chinese; Danish; genetic overlap; twins

\section{INTRODUCTION}

Cardiovascular disease is the leading cause of mortality and morbidity worldwide. High blood pressure is known as the most important modifiable risk factor for cardiovascular disease. ${ }^{1}$ Efficient control and adequate management of high blood pressure can therefore have a significant impact on public health. Blood pressure is a complex phenotype involving many control systems operated by physiological mechanisms under multiple genetic and environmental regulations ${ }^{2}$ that may have a diverse pattern of regulation across different ethnic populations. For example, genetic factors have been estimated to account for as much as $71 \%$ of the total variation in systolic blood pressure (SBP) in Danish twins ${ }^{3}$ and $58 \%$ in Chinese twins. ${ }^{4}$ The moderate to high influence genetic factors have on blood pressure has led to a considerable amount of research aimed at identifying the molecular genetic basis of blood pressure regulation; recent research activity has intensified, driven by the rapid development of highthroughput analyses at the genome level.

SBP represents the maximum exerted pressure on the vessels when the heart contracts (when the heart is beating); diastolic blood pressure $(\mathrm{DBP})$ is the minimum pressure in the vessels when the heart relaxes (when the heart is resting between beats and refilling with blood). Often more attention is given to SBP as a major risk factor for cardiovascular disease. ${ }^{5}$ Although SBP and DBP represent the maximum and minimum blood pressure in the arteries, respectively, results from recent genome-wide association studies (GWAS) indicate that there are genetic variants for SBP and DBP shared in both eastern and western populations. ${ }^{6,7}$ For example, of the 29 genetic variants associated with SBP at a genome-wide significance level $(P<2.5 \mathrm{e}-08)$ reported in the study by Ehret et al. ${ }^{7} 23$ variants were also significantly associated with DBP. Genome-wide association study is based on common surrogate variants with limited depth of genomic coverage, ${ }^{8}$ and as a result more research is needed to provide an overall picture of the extent of genetic relatedness between SBP and DBP. Based on an existing Danish-Chinese collaboration network on twin research, the aim of this study is to determine the genetic factors responsible for blood pressure and to evaluate the phenotypic correlation between SBP and DBP across populations using bivariate models ${ }^{9}$ to compare Danish and Chinese twins (representing western

${ }^{1}$ Unit of Human Genetics, Institute of Clinical Research, University of Southern Denmark, Odense, Denmark; ${ }^{2}$ Qingdao Center for Disease Control and Prevention, Qingdao, China; ${ }^{3}$ Department of Public Health, Qingdao University Medical College, Qingdao, China; ${ }^{4}$ Institute of Public Health, University of Southern Denmark, Odense, Denmark; ${ }^{5}$ Department of Clinical Genetics, Odense University Hospital, Odense, Denmark and ${ }^{6}$ Institute for Regional Health Research, University of Southern Denmark and Odense Patient Data Explorative Network (OPEN), Odense University Hospital, Odense, Denmark

Correspondence: S Li, Unit of Human Genetics, Institute of Clinical Research, University of Southern Denmark, Sdr. Boulevard 29, DK-5000 Odense, Denmark.

E-mail: sli@health.sdu.dk

Received 27 January 2014; revised 14 March 2014; accepted 18 March 2014; published online 15 May 2014 
and eastern populations, respectively). The results of analyses of Danish and Chinese twins may provide mutual validation and will be compared to determine whether there are ethnic differences in the role that genetics and environment have in blood pressure variation and correlation.

\section{METHODS}

\section{The Danish twin samples}

The collection of Danish twins used in the present study has been described previously. ${ }^{10}$ In brief, Danish twins were recruited from two cohorts of the population-based Danish Twin Registry, with cohort I covering twins born between 1931 and 1952 and cohort II born between 1953 and 1982. Twins who consented to participate were selected based on the exclusion criteria that excluded participants with diabetes, cardiovascular diseases, physical disabilities, or those who were pregnant, breast feeding or required regular medication. The final sample consisted of 756 twin pairs (309 monozygotic (MZ) pairs, 447 dizygotic (DZ) pairs) collected at two clinical investigation sites in Odense and Copenhagen, Denmark. Twin zygosity was determined by nine polymorphic DNA microsatellite markers.

Blood pressure was measured following a standard procedure using a conventional mercurial sphygmomanometer. Three measurements were taken from each subject, with at least $1 \mathrm{~min}$ between each measurement. The mean of these three values was calculated and used in subsequent analyses. Body weight was measured to the nearest $0.1 \mathrm{~kg}$ using a standing beam scale. Height was measured to the nearest centimeter using a vertical scale with a horizontal moving headboard. Body mass index was calculated as weight $(\mathrm{kg})$ divided by the square of height $(\mathrm{m})$. The Danish part of the study was approved by the Danish regional ethics committees and the Danish Data Protection Agency with journal number: S-VF-19970271.

\section{The Chinese twin samples}

The sampling of Chinese twins was based on the Qingdao Twin Registry ${ }^{11}$ established in 2001 at the Qingdao Center for Disease Control and Prevention (Qingdao CDC). Twins were identified through the local disease control network and residence registry. Exclusion criteria removed those who were pregnant, breastfeeding, those with diabetes and/or cardiovascular disease or who had been taking blood pressure or weight-reducing medications within the previous month. Data were collected from a total of 325 pairs of twins (183 MZ twin pairs and $142 \mathrm{DZ}$ twin pairs). Zygosity of same-sex twin pairs was determined by DNA testing using 16 short tandem repeat DNA markers at the central laboratory of the Qingdao Blood Bank.

Body measurements and blood pressure were taken using the procedures described for the Danish twins. The Chinese part of the study was approved by the local ethics committee at Qingdao CDC, Qingdao, China.

Both Danish and Chinese blood pressure data were log transformed to ensure a normal or approximately normal distribution. Most importantly, the log transformation helped minimize the correlation between blood pressure magnitude and the standard error of the mean. ${ }^{12}$ In both sample sets, blood pressure values more than 3 s.d.'s from the mean were excluded from subsequent analyses.

\section{Bivariate modeling on twins}

We introduced a bivariate model jointly to analyze SBP and DBP (Figure 1) using the typical structural equation modeling (s.e.m.) approach. ${ }^{9}$ In this approach, variances in the observed traits (SBP and DBP) and their covariance are decomposed into latent additive genetic (A), shared environmental (C), and unique environmental (E) components. Based on variance estimates, the genetic correlation $\left(r_{\mathrm{g}}\right)$ can be calculated as $r_{\mathrm{g}}=\frac{\operatorname{cov}_{\mathrm{g}}(\mathrm{SBP}, \mathrm{DBP})}{\sqrt{\operatorname{var}_{\mathrm{g}}(\mathrm{SBP}) \operatorname{var}_{\mathrm{g}}(\mathrm{DBP})}}$ where $\operatorname{var}_{\mathrm{g}}(\mathrm{SBP})$ and $\operatorname{var}_{\mathrm{g}}(\mathrm{DBP})$ are the additive genetic variance of SBP and DBP, respectively, and $\operatorname{cov}_{\mathrm{g}}(\mathrm{SBP}, \mathrm{DBP})$ is their genetic covariance. Likewise, correlations for common environmental $\left(r_{\mathrm{c}}\right)$ and unique environmental $\left(r_{\mathrm{e}}\right)$ factors can be calculated. In s.e.m., parameter estimates are obtained using a fitting function that minimizes the difference between the observed covariance matrix and the expected covariance matrix implied by the model, assuming bivariate normality.

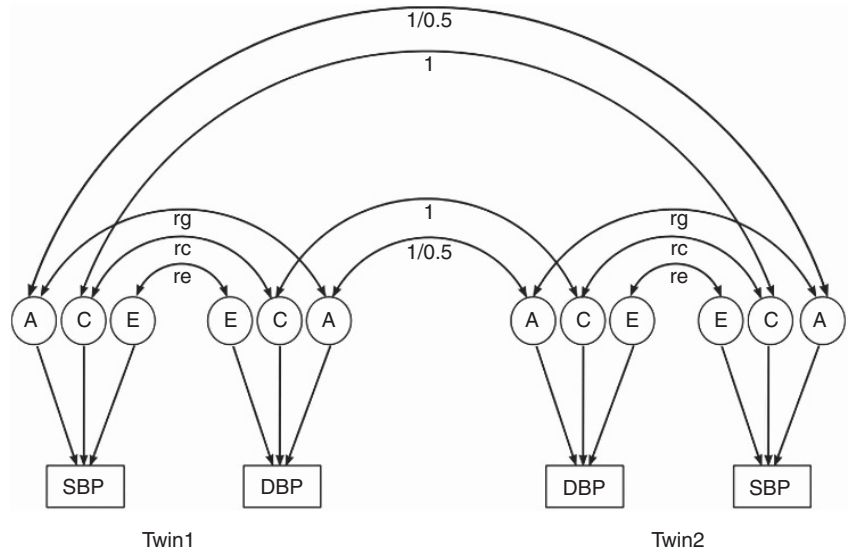

Figure 1 Path diagram of the bivariate twin model applied to systolic blood pressure (SBP) and diastolic blood pressure (DBP), assuming additive genetic (A), common environmental (C) and unique environmental (E) components in the variances and covariance of SBP and DBP, with $r_{\mathrm{g}}, r_{\mathrm{c}}$ and $r_{\mathrm{e}}$ standing for twin correlation of the $\mathrm{A}, \mathrm{C}$ and $\mathrm{E}$ components, respectively.

Table 1 Descriptive statistics for Danish and Chinese twins

\begin{tabular}{|c|c|c|c|c|}
\hline \multirow[b]{2}{*}{ Basic statistics } & \multicolumn{2}{|r|}{ Danish twins } & \multicolumn{2}{|r|}{ Chinese twins } \\
\hline & Median & 2.5-97.5\% Quantiles & Median & 2.5-97.5\% Quantiles \\
\hline Age (years) & 38 & $19-57$ & 40 & $20-60$ \\
\hline BMI $\left(\mathrm{kg} \mathrm{m}^{-2}\right)$ & 24 & $18.8-32$ & 24 & $18.6-32$ \\
\hline SBP (mm Hg) & 116 & $94-146$ & 120 & $100-160$ \\
\hline $\mathrm{DBP}(\mathrm{mm} \mathrm{Hg})$ & 68 & $50-90$ & 80 & 60-106 \\
\hline
\end{tabular}

Abbreviations: BMI, body mass index; DBP, diastolic blood pressure; SBP, systolic blood pressure.

Table 2 Within- and cross-trait correlation in MZ and DZ twin pairs

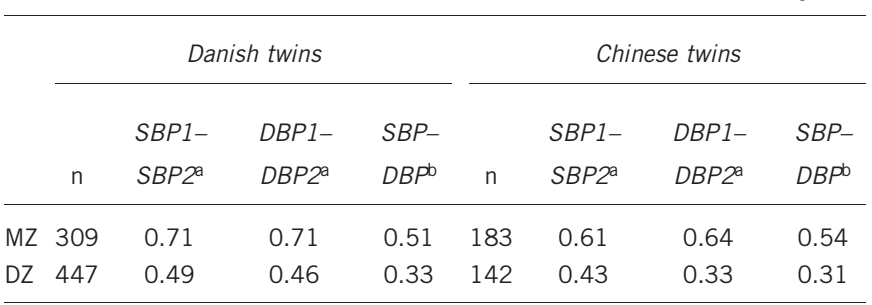

Abbreviations: DZ, dizygotic; MZ, monozygotic

aCross twin within-trait correlation.

Cross twin cross-trait correlation.

Model fitting was carried out separately for Danish and Chinese twins using the Mx software package, ${ }^{13}$ with age, sex and body mass index included as covariates. Considering that data on twins reared together does not contain enough information to tease out the contrasting effects of common environmental (C) and dominant genetic (D) components, ${ }^{9}$ our model fitting started with consideration of both the bivariate ACE and the bivariate ADE models, with the latter including additive genetic, dominant genetic and unique environmental effects. As a rule of thumb, the presence of dominance can be recognized when DZ correlation is much lower than half of MZ correlation. Based on twin correlation in the results section, the ADE model was rejected because each DZ correlation was more than half of the corresponding MZ correlation (Table 2), which does not support the presence of a dominant genetic effect. The full bivariate ACE and its nested bivariate 
models (AE, CE, E) were fitted. The performances of the different bivariate models were compared using Akaike's information criterion, ${ }^{14}$ such that the model with the lowest Akaike's information criterion reflected the best balance between goodness-of-fit and parsimony. Meanwhile, the fitting of nested models enabled assessment of statistical significance of the A, C and E component using the likelihood ratio $\left(\chi^{2}\right)$ test at a significance level of $P<0.05$. This led to the most parsimonious (or 'best fitting') model in which the pattern of variances and covariances was explained by as few parameters as possible. In all model fitting, bootstrap resampling with 100 replicates was used to obtain $95 \%$ confidence intervals (CIs) for the estimated model parameters.

\section{RESULTS}

Table 1 presents the basic characteristics of the Danish and Chinese twins. The age structures of the two samples are very similar, with the median age of the Chinese twins approximately 2 years older than that of the Danish twins. Both the median and the 2.5-97.5 percent quantiles for body mass index are very similar in the two samples. Both SBP and DBP tend to be higher in the Chinese than in the Danish twins; however, there is large overlap in the 2.5-97.5 percent quantiles. Table 2 shows the correlation within and cross traits in MZ and DZ twins. All correlation coefficients are highly significant with $P<0.001$. The phenotypic correlation coefficients are all higher in $\mathrm{MZ}$ twins than DZ twins, which suggest genetic control over the variation (within-trait) in SBP, DBP as well as over the covariation (cross-trait) between SBP and DBP. In all cases, DZ correlation is greater than half of the MZ correlation, suggesting that the ACE models can be appropriately applied to the data.

We first fitted the full bivariate ACE models to Danish and Chinese twins (Table 3). The Danish twins displayed higher genetic but lower unique environmental impact on SBP and DBP covariance when compared with the Chinese twins. The proportion of genetic contribution to SBP-DBP correlation in Danish twins was 0.56 (95\% CI: 0.34-0.76); the value in the Chinese twins was 0.39 (95\% CI: 0.02-0.71). The difference is not statistically significant because of the overlapping 95\% CIs. In Chinese twins, the unique environmental component played a larger role in SBP-DBP correlation $(0.39,95 \%$ CI: $0.30-0.51)$ than in the Danish twins $(0.30,95 \%$ CI: $0.24-0.37)$ with partially overlapping $95 \%$ CIs. Based on variance and covariance estimates, $r_{\mathrm{g}}, r_{\mathrm{c}}$ and $r_{\mathrm{e}}$ were calculated as $0.71,0.79$ and 0.71 , respectively, for the Danish twins and 0.80, 0.95 and 0.64, respectively, for the Chinese twins (Table 3). The likelihood ratio test applied to the nested models formed by dropping the $\mathrm{A}, \mathrm{C}$ and $\mathrm{E}$ components in SBP-DBP covariance in each sample showed very highly significant genetic and unique environmental contributions to SBP-DBP correlation. However, the additive genetic effect in the Chinese twins displayed borderline significance. In both samples, the contributions of common environmental factors were insignificant as indicated by 95\% CIs that included zero ( $-0.04-0.33$ for Danish twins; -0.04 0.51 for Chinese twins).

We next compared performances of the nested models with the full ACE models using Akaike's information criterion. Consistent with the results from likelihood ratio test, the model without the $\mathrm{C}$ component that correlated SBP and DBP was chosen as the best fitting model in both samples. In Table 4, we show the estimated genetic and environmental components included in the best fitting model. Figure 2 shows the proportions that $\mathrm{A}$ and $\mathrm{E}$ components contribute to SBP-DBP correlation. The figure shows that the correlation between SBP and DBP is mainly the result of genetic factors in both samples; these genetic factors are more pronounced in Danish than in Chinese twins. However, unique environment has a larger role in the SBP-DBP correlation in Chinese twins than Danish twins. Neither result is statistically significant with respect to ethnic difference with overlapping 95\% CIs. In Table 4, we also show the estimated $r_{\mathrm{g}}$ and $r_{\mathrm{e}}$ from the best models fitted to Danish and Chinese twins. In contrast to the proportion of genetic and unique environmental influences on the correlation between SBP and DBP, a higher $r_{\mathrm{g}}$ was estimated in Chinese twins $(0.81,95 \%$ CI: 0.73-0.88) compared with the Danish twins $(0.71,95 \%$ CI: $0.67-0.75)$, whereas a higher $r_{\mathrm{e}}$ was observed in Danish twins (0.70, 95\% CI: 0.65-0.75) than in Chinese twins $(0.63$, $95 \%$ CI: $0.54-0.71)$. None of these results was statistically significant between the two samples.

In addition, the best fitting model estimated significant differences in the additive genetic and unique environmental influences on SBP with no overlapping $95 \%$ CIs for the genetic (0.72, 95\% CI: $0.67-0.76$ in Danish; 0.54, 95\% CI: 0.44-0.63 in Chinese twins) and unique environmental $(0.28,95 \%$ CI: $0.24-0.33$ in Danish; 0.46 , 95\% CI

Table 3 Variance components and correlation coefficients for A, C and E from bivariate models fitted to blood pressure in Danish and Chinese twins

\begin{tabular}{|c|c|c|c|c|c|c|}
\hline & \multicolumn{3}{|c|}{ Danish twins } & \multicolumn{3}{|c|}{ Chinese twins } \\
\hline & $A$ & C & $E$ & $A$ & C & $E$ \\
\hline \multicolumn{7}{|l|}{$S B P$} \\
\hline Variance & $8.3 e-03$ & $1.1 \mathrm{e}-03$ & $3.9 e-03$ & $4.2 e-03$ & $3.6 e-03$ & $7.0 e-03$ \\
\hline Proportion & $0.62(0.45,0.75)$ & $0.09(0.00,0.24)$ & $0.29(0.25,0.34)$ & $0.28(0.01,0.60)$ & $0.24(0.00,0.50)$ & $0.47(0.39,0.59)$ \\
\hline \multicolumn{7}{|l|}{$D B P$} \\
\hline Variance & $1.1 \mathrm{e}-02$ & $4.2 e-03$ & $6.8 e-03$ & $8.4 e-03$ & $2.2 \mathrm{e}-03$ & $8.3 e-03$ \\
\hline Proportion & $0.50(0.32,0.68)$ & $0.19(0.03,0.34)$ & $0.31(0.26,0.37)$ & $0.45(0.17,0.62)$ & $0.12(0.00,0.36)$ & $0.43(0.36,0.52)$ \\
\hline \multicolumn{7}{|l|}{$S B P-D B P$} \\
\hline Variance & $6.8 e-03$ & $1.7 e-03$ & $3.6 e-03$ & $4.8 e-03$ & $2.7 e-03$ & $4.8 e-03$ \\
\hline Proportion & $0.56(0.34,0.76)$ & $0.14(-0.04,0.33)$ & $0.30(0.24,0.37)$ & $0.39(0.02,0.71)$ & $0.22(-0.04,0.51)$ & $0.39(0.30,0.51)$ \\
\hline$r_{\mathrm{g}}, r_{\mathrm{c}}, r_{\mathrm{e}}$ & $0.71(0.57,0.81)$ & $0.79(-1.00,1.00)$ & $0.71(0.65,0.76)$ & $0.80(0.80,1.00)$ & $0.95(-1.00,1.00)$ & $0.64(0.57,0.70)$ \\
\hline$\chi^{2}$ & 26.76 & 1.99 & 262.25 & 3.72 & 1.96 & 115.91 \\
\hline$P$-value & $2.3 e-07$ & 0.16 & $5.55 e-59$ & $5.38 e-02$ & 0.16 & $4.97 e-27$ \\
\hline
\end{tabular}

Abbreviations: DBP, diastolic blood pressure; $r_{\mathrm{c}}$, common environmental correlation; $r_{\mathrm{e}}$, unique environmental correlation; $r_{\mathrm{g}}$, genetic correlation; SBP, systolic blood pressure. 


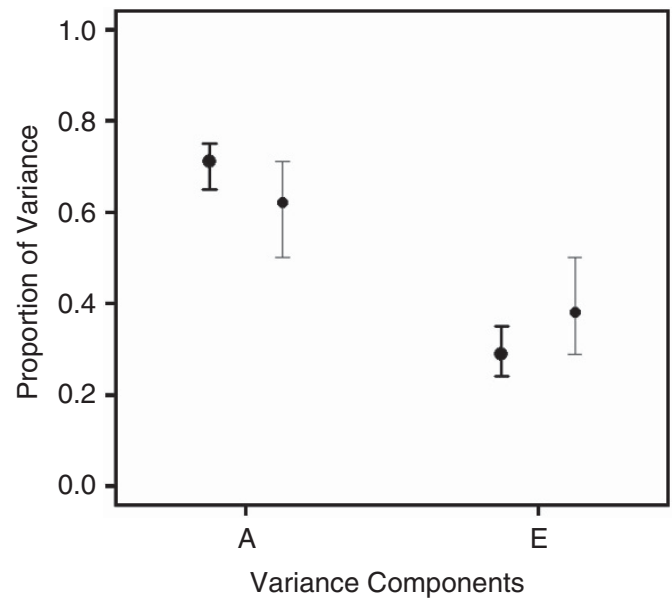

Figure 2 Estimated proportions with 95\% confidence intervals (Cls) of A and $E$ components for the covariance of systolic blood pressure (SBP) and diastolic blood pressure (DBP) in the best fitting model. The thick error bars are for Danish twins and the thin error bars are for Chinese twins.
0.37-0.56 in Chinese twins) components. The same pattern of genetic and environmental influences holds for DBP with slightly overlapping 95\% CIs of the A and E components (Table 4 and Figure 3).

\section{DISCUSSION}

The results of bivariate modeling of blood pressure data taken from Danish and Chinese twins both indicated that there was a significant genetic component in the phenotypic correlation between SBP and DBP, which exists in two populations of distinct ethnic, cultural and environmental circumstances. The consistent findings in our separate analyses of two independent samples serve as mutual validation of our conclusion. In an earlier study, Schieken et al. ${ }^{15}$ reported a genetic proportion of $74 \%$ in SBP-DBP covariance in Caucasian boys and girls with an average age of 11 years. The result of that study is very close to our estimate of 0.71 in Danish twins, which represent middleaged Caucasians. The existence of shared genetic regulation of SBP and DBP was also reported in a very recent study of Brazilian nuclear families; in that study, the genetic correlation coefficient was $0.67 .{ }^{16}$ Recent genetic association studies have reported common singlenucleotide polymorphisms that significantly affect both SBP and DBP, and provide molecular evidence for shared genetic mechanisms that

Table 4 Variance and covariance components in the best fitting models for SBP and DBP in Danish and Chinese twins

\begin{tabular}{|c|c|c|c|c|}
\hline & \multicolumn{2}{|c|}{ Danish twins } & \multicolumn{2}{|c|}{ Chinese twins } \\
\hline & $A$ & E & $A$ & E \\
\hline Variance & $9.4 e-03$ & $3.8 e-03$ & $8.0 e-03$ & $6.7 e-03$ \\
\hline Proportion & $0.72(0.67,0.76)$ & $0.28(0.24,0.33)$ & $0.54(0.44,0.63)$ & $0.46(0.37,0.56)$ \\
\hline Proportion & $0.70(0.65,0.75)$ & $0.30(0.25,0.35)$ & $0.57(0.47,0.65)$ & $0.43(0.35,0.53)$ \\
\hline \multicolumn{5}{|l|}{$S B P-D B P$} \\
\hline Covariance & $8.6 e-03$ & $3.5 e-03$ & $7.5 e-03$ & $4.6 e-03$ \\
\hline Proportion & $0.71(0.65,0.75)$ & $0.29(0.24,0.35)$ & $0.62(0.50,0.71)$ & $0.38(0.29,0.50)$ \\
\hline
\end{tabular}

Abbreviations: DBP, diastolic blood pressure; $r_{\mathrm{c}}$, common environmental correlation; $r_{\mathrm{e}}$, unique environmental correlation; $r_{\mathrm{g}}$, genetic correlation; SBP, systolic blood pressure.
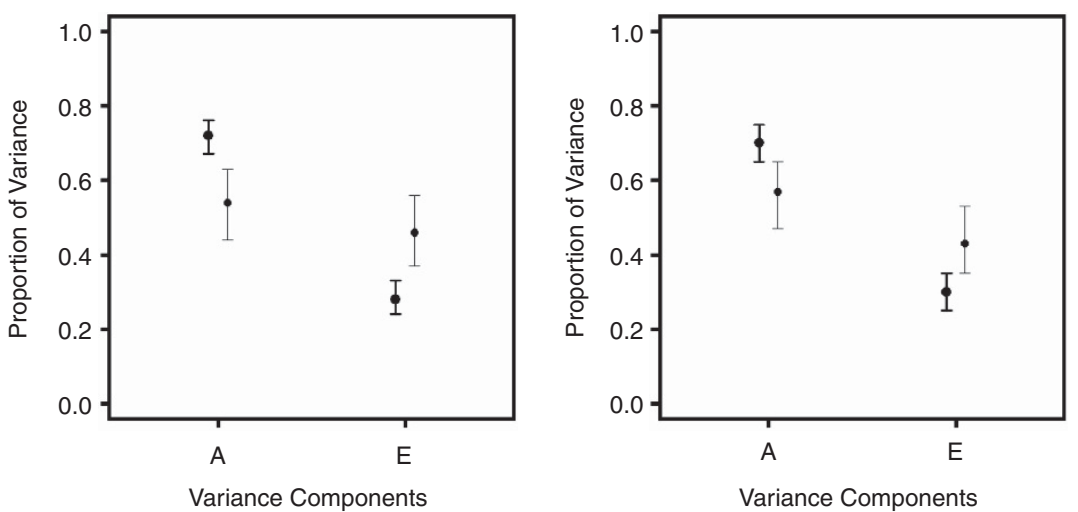

Figure 3 Estimated proportion of variance components for systolic blood pressure (SBP) (left panel) and diastolic blood pressure (DBP) (right panel) in the best fitting model with $95 \%$ confidence intervals (Cls) empirically obtained using bootstrap resampling. The thick error bars are for Danish twins and the thin error bars are for Chinese twins. 
are responsible for SBP and DBP coregulation in both Caucasians and East Asians. ${ }^{6,7}$ The estimated proportion of genetic components that are responsible for blood pressure correlation may help determine potential heritable genetic variations that have not yet been identified by linkage and association studies. Considering that genetic regulation may have a large role in the correlation between SBP and DBP, additional functional and static genetic variants that affect both SBP and DBP are expected to be discovered using functional genomics, next-generation sequencing and epigenetic approaches. ${ }^{17,18}$

A general pattern of ethnic differences in genetic and environmental contributions to blood pressure is revealed by the results of the present study. Genetic control over blood pressure and the correlation between SBP and DBP are higher in the Danish sample, whereas more unique environmental influences were observed in the Chinese sample (Tables 3 and 4). As displayed in Figures 2 and 3, although the same pattern holds for SBP, DBP and their correlation, the results were only significant for SBP, with no overlapping 95\% CIs of the A and E components between Danish and Chinese twins. In view of the limited sample sizes, particularly in the case of Chinese twins, largescale studies and more detailed genetic investigations are required to determine whether there is a clear pattern of ethnic differences in factors influencing blood pressure.

As indicated in Table 4, the estimated additive genetic component responsible for SBP-DBP covariance is higher in Danish twins (0.71, 95\% CI: 0.65-0.75) than in Chinese twins (0.62, 95\% CI: 0.50-0.71). However, the results of genetic correlation show the opposite result, with higher genetic correlation in Chinese twins (0.81, 95\% CI: $0.73-$ 0.88) than Danish twins (0.71, 95\% CI: 0.67-0.75). Although these differences are not statistically significant when considering their overlapping confidence intervals, the reversed pattern does deserve some discussion. Note that the estimated proportion of the additive genetic component is a measurement of the relative importance of genetic factors taking into account environmental effects, whereas genetic correlation measures the absolute covariation between the additive genetic variances of SBP and DBP. A high genetic correlation could indicate a shared genetic basis for SBP and DBP in a number of genetic variants, that is, pleiotropic genes. A strong common genetic basis can be diluted when large environmental effects interfere at the time the level of genetic contribution is calculated, which might be the case for the Chinese twins. More molecular genetic studies are required to verify our hypothesis.

In both full and nested models, the unique environmental effects on blood pressure and the correlation between SBP and DBP are significant in both Danish and Chinese twins, which suggests that the effects of the individual environment is crucial for explaining blood pressure variation and covariation. Although the importance of unique environmental factors was consistent between the sample groups, we note that there is a noticeable ethnic difference in the two samples, with a higher proportion of $\mathrm{E}$ components in Chinese than Danish twins. This is clearly demonstrated in Figure 3, which indicates that the $95 \%$ CIs of the E component do not overlap for SBP $(P<0.05)$ and only slightly overlap for DBP (borderline significance). These results indicate the special importance of individual environmental factors, including social and behavioral factors such as lifestyle (hectic and stressful life), occupation (sedentary work) and dietary habits (high dietary sodium) ${ }^{19-21}$ in controlling blood pressure in the Chinese population.

Overall, we have identified relatively high genetic overlap between SBP and DBP, providing strong evidence that there are common genetic mechanisms responsible for regulating SBP and DBP in both Chinese (eastern) and Danish (western) populations. Our results also suggest that individual environment has a large role in blood pressure variation; measures that promote healthy lifestyles should efficiently reduce the risk of hypertension and cardiovascular problems, particularly in the Chinese population.

\section{CONFLICT OF INTEREST}

The authors declare no conflict of interest.

\section{ACKNOWLEDGEMENTS}

This work was jointly supported by the Novo Nordisk Foundation 2011 Grant for Medical Research (project no. 14162) and the Region of South Denmark PhD Grant 2012 j.nr. 127676.

1 Grossman E. Blood pressure: the lower, the better. Diabetes Care 2011; 34 S308-S312.

2 Arora P, Newton-Cheh C. Blood pressure and human genetic variation in the genera population. Curr Opin Cardiol 2010; 25: 229-237.

3 Li S, Duan HM, Pang Z, Zhang D, Duan HP, Hjelmborg J, Tan Q, Kruse T, Kyvik KO. Heritability of eleven metabolic phenotypes in Danish and Chinese twins: a cross population comparison. Obesity 2013; 21: 1908-1914.

4 Duan H, Pang Z, Zhang D, Li S, Kruse TA, Kyvik KO, Christensen K, Tan Q. Genetic and environmental dissections of sub-phenotypes of metabolic syndrome in the Chinese population: a twin-based heritability study. Obes Facts 2011; 4: 99-104.

5 Peters SA, Huxley RR, Woodward M. Comparison of the sex-specific associations between systolic blood pressure and the risk of cardiovascular disease: a systematic review and meta-analysis of 124 cohort studies, including 1.2 million individuals. Stroke 2013; 44: 2394-2401.

6 Kato N, Takeuchi F, Tabara Y, Kelly TN, Go MJ, Sim X, Tay WT, Chen CH, Zhang Y, Yamamoto K, Katsuya T, Yokota M, Kim YJ, Ong RT, Nabika T, Gu D, Chang LC, Kokubo Y, Huang W, Ohnaka K, Yamori Y, Nakashima E, Jaquish CE, Lee JY, Seielstad M, Isono M, Hixson JE, Chen YT, Miki T, Zhou X, Sugiyama T, Jeon JP Liu JJ, Takayanagi R, Kim SS, Aung T, Sung YJ, Zhang X, Wong TY, Han BG, Kobayashi S, Ogihara T, Zhu D, Iwai N, Wu JY, Teo YY, Tai ES, Cho YS, He J. Meta-analysis of genome-wide association studies identifies common variants associated with blood pressure variation in east Asians. Nat Genet 2011; 43 531-538.

7 Ehret GB, Munroe PB, Rice KM, Bochud M, Johnson AD, Chasman DI, Smith AV, Tobin MD, Verwoert GC, Hwang SJ, Pihur V, Vollenweider P, O'Reilly PF, Amin N Bragg-Gresham JL, Teumer A, Glazer NL, Launer L, Zhao JH, Aulchenko Y, Heath S, Sõber S, Parsa A, Luan J, Arora P, Dehghan A, Zhang F, Lucas G, Hicks AA Jackson AU, Peden JF, Tanaka T, Wild SH, Rudan I, Igl W, Milaneschi Y, Parker AN Fava C, Chambers JC, Fox ER, Kumari M, Go MJ, van der Harst P, Kao WH, Sjögren M, Vinay DG, Alexander $M$, Tabara $Y$, Shaw-Hawkins $S$, Whincup PH, Liu Y, Shi G, Kuusisto J, Tayo B, Seielstad M, Sim X, Nguyen KD, Lehtimäki T, Matullo G, Wu Y, Gaunt TR, Onland-Moret NC, Cooper MN, Platou CG, Org E, Hardy R, Dahgam S Palmen J, Vitart V, Braund PS, Kuznetsova T, Uiterwaal CS, Adeyemo A, Palmas W, Campbell H, Ludwig B, Tomaszewski M, Tzoulaki I, Palmer ND, CARDloGRAM consortium; CKDGen Consortium; KidneyGen Consortium; EchoGen consortium CHARGE-HF consortium, Aspelund T, Garcia M, Chang YP, O'Connell JR, Steinle NI, Grobbee DE, Arking DE, Kardia SL, Morrison AC, Hernandez D, Najiar S, McArdle WL, Hadley D, Brown MJ, Connell JM, Hingorani AD, Day IN, Lawlor DA, Beilby JP, Lawrence RW, Clarke R, Hopewell JC, Ongen H, Dreisbach AW, Li Y, Young JH, Bis JC Kähönen M, Viikari J, Adair LS, Lee NR, Chen MH, Olden M, Pattaro C, Bolton JA Köttgen A, Bergmann S, Mooser V, Chaturvedi N, Frayling TM, Islam M, Jafar TH, Erdmann J, Kulkarni SR, Bornstein SR, Grässler J, Groop L, Voight BF, Kettunen J, Howard P, Taylor A, Guarrera S, Ricceri F, Emilsson V, Plump A, Barroso I, Khaw KT, Weder AB, Hunt SC, Sun YV, Bergman RN, Collins FS, Bonnycastle LL, Scott LJ, Stringham HM, Peltonen L, Perola M, Vartiainen E, Brand SM, Staessen JA, Wang TJ, Burton PR, Soler Artigas M, Dong Y, Snieder H, Wang X, Zhu H, Lohman KK Rudock ME, Heckbert SR, Smith NL, Wiggins KL, Doumatey A, Shriner D, Veldre G, Viigimaa M, Kinra S, Prabhakaran D, Tripathy V, Langefeld CD, Rosengren A, Thelle DS, Corsi AM, Singleton A, Forrester T, Hilton G, McKenzie CA, Salako T, Iwai N, Kita Y, Ogihara T, Ohkubo T, Okamura T, Ueshima H, Umemura S, Eyheramendy $\mathrm{S}$, Meitinger T, Wichmann HE, Cho YS, Kim HL, Lee JY, Scott J, Sehmi JS, Zhang W, Hedblad B, Nilsson P, Smith GD, Wong A, Narisu N, Stančáková A, Raffel LJ, Yao J, Kathiresan S, O'Donnell CJ, Schwartz SM, Ikram MA, Longstreth WT Jr, Mosley TH, Seshadri S, Shrine NR, Wain LV, Morken MA, Swift AJ, Laitinen J, Prokopenko I, Zitting P, Cooper JA, Humphries SE, Danesh J, Rasheed A, Goel A, Hamsten A, Watkins $H$, Bakker SJ, van Gilst WH, Janipalli CS, Mani KR, Yajnik CS, Hofman A Mattace-Raso FU, Oostra BA, Demirkan A, Isaacs A, Rivadeneira F, Lakatta EG, Orru M, Scuteri A, Ala-Korpela M, Kangas AJ, Lyytikäinen LP, Soininen P, Tukiainen T, Würtz P, Ong RT, Dörr M, Kroemer HK, Völker U, Völzke H, Galan P, Hercberg S, Lathrop M, Zelenika D, Deloukas P, Mangino M, Spector TD, Zhai G, Meschia JF, Nalls MA, Sharma P, Terzic J, Kumar MV, Denniff M, Zukowska-Szczechowska E, Wagenknecht LE, Fowkes FG, Charchar FJ, Schwarz PE, Hayward C, Guo X, Rotimi C, Bots ML, Brand E, Samani NJ, Polasek O, Talmud PJ, Nyberg F, Kuh D, Laan M, 
Hveem K, Palmer LJ, van der Schouw YT, Casas JP, Mohlke KL, Vineis P, Raitakari O, Ganesh SK, Wong TY, Tai ES, Cooper RS, Laakso M, Rao DC, Harris TB, Morris RW, Dominiczak AF, Kivimaki M, Marmot MG, Miki T, Saleheen D, Chandak GR, Coresh J, Navis G, Salomaa V, Han BG, Zhu X, Kooner JS, Melander O, Ridker PM, Bandinelli S, Gyllensten UB, Wright AF, Wilson JF, Ferrucci L, Farrall M, Tuomilehto J, Pramstaller PP, Elosua R, Soranzo N, Sijbrands EJ, Altshuler D, Loos RJ, Shuldiner AR, Gieger C, Meneton P, Uitterlinden AG, Wareham NJ, Gudnason V, Rotter JI, Rettig R, Uda M, Strachan DP, Witteman JC, Hartikainen AL, Beckmann JS, Boerwinkle E, Vasan RS, Boehnke M, Larson MG, Järvelin MR, Psaty BM, Abecasis GR, Chakravarti A, Elliott P, van Duijn CM, Newton-Cheh C, Levy D, Caulfield MJ, Johnson T. Genetic variants in novel pathways influence blood pressure and cardiovascular disease risk. Nature 2011; 478: 103-109.

8 Spencer CC, Su Z, Donnelly P, Marchini J. Designing genome-wide association studies: sample size, power, imputation, and the choice of genotyping chip. PLoS Genet 2009; 5: e1000477.

9 Rijsdijk FV, Sham PC. Analytic approaches to twin data using structural equation models. Brief Bioinform 2002; 3: 119-133.

10 Benyamin B, Sørensen TI, Schousboe K, Fenger M, Visscher PM, Kyvik KO. Are there common genetic and environmental factors behind the endophenotypes associated with the metabolic syndrome? Diabetologia 2007; 50: 1880-1888.

11 Duan H, Ning F, Zhang D, Wang S, Zhang D, Tan Q, Tian X, Pang Z. The Qingdao Twin Registry: a status update. Twin Res Hum Genet 2013; 16: 79-85.

12 Lew M. Good statistical practice in pharmacology Problem 1. Br J Pharmacol 2007; 152: 295-298.
13 Neale MC, Boker SM, Xie G, Maes HH. Mx: Statistical Modeling 6th edn. Department of Psychiatry: Richmond, VA, USA, 2003.

14 Akaike H. A new look at the statistical model identification. IEEE Trans Automat Control 1974; 19: 716-723.

15 Schieken RM, Mosteller M, Goble MM, Moskowitz WB, Hewitt JK, Eaves LJ, Nance WE. Multivariate genetic analysis of blood pressure and body size. The Medical College of Virginia Twin Study. Circulation 1992; 86: 1780-1788.

16 Forjaz CM, Bartholomeu T, Rezende JS, Oliveira JA, Basso L, Tani G, Prista A, Maia JR. Genetic and environmental influences on blood pressure and physical activity: a study of nuclear families from Muzambinho, Brazil. Brazil J Med Biol Res 2012; 45: 1269-1275.

17 Zhang D, Li S, Tan Q, Pang Z. Twin-based DNA methylation analysis takes the center stage of studies of human complex diseases. J Genet Genom 2012; 39: $581-586$.

18 Tan Q, Christiansen L, Thomassen M, Kruse TA, Christensen K. Twins for epigenetic studies of human aging and development. Ageing Res Rev 2013; 12: 182-187.

19 Markovitz JH, Mathews KA, Kannel WB, Cobb JL, D'Agostino RB. Psychologic predictors of hypertension in the Framingham study: is there tension in hypertension? JAMA 1993; 270: 2439-2443.

20 Beunza JJ, Martínez-González MA, Ebrahim S, Bes-Rastrollo M, Núñez J, Martínez JA, Alonso A. Sedentary behaviors and the risk of incident hypertension: the SUN Cohort. Am J Hypertens 2007; 20: 1156-1162.

21 Yan L, Li N, Wu Y. Salt restriction and challenges in China for hypertension control. Curr Cardiovasc Risk Rep 2011; 5: 180-186. 